\title{
A REVIEW OF RELATIONSHIPS BETWEEN ACTIVE LIVING AND DETERMINANTS OF HEALTH
}

\author{
C. JAMES FRANKISH*, C. DAWNE MILLIGAN and COLLEEN REID \\ Institute of Health Promotion Research, University of British Columbia, Room 308, Library Processing \\ Building, Vancouver, BC, Canada V6T 1 Z3
}

\section{INTRODUCTION}

The significance of recreation, physical activity and leisure to one's well-being is exemplified in the ideal of a "sound mind in a sound body". Physical activity is a key contributor to health. Accumulating evidence indicates that sedentariness is a risk factor for cardiovascular and other major diseases (Havighurst, 1974; Folsom et al., 1985; Anonymous, 1993; Bjorntorp, 1995; Duncan et al., 1995a,b,c; Puddey and Beilin, 1995; Pate et al., 1995; Whaley and Blair, 1995; Anonymous, 1996; Francis, 1996, Fries, 1996; Mensink et al., 1996; Wenger, 1996; Folsom et al., 1997). Even moderate levels of activity confer health benefits, and for most people, additional health benefits may be derived by becoming more active. Moderating factors for prevention of major diseases which may be accessed through moderate levels of activity include weight management and stress reduction. Despite extensive media coverage of such evidence, the level of physical activity in the lives of many North Americans remains suboptimal (Pate et al., 1995; Anonymous, 1996).

Health is a resource rather than a reason for living. As such, it connotes a positive concept emphasizing social and personal resources as well as physical capacities. Such capacities vary according to one's life circumstances. Active living occurs, or may fail to occur, within a social context (Yoshida et al., 1988; Yoshioka, 1988; Yeager et al., 1993; Collette et al., 1994; Heath and Smith, 1994; Caltabiano, 1995; Frederick and Shaw, 1995; Pitter and Andrews, 1997). To understand the relationships between active living and determinants of health one must consider both personal lifestyle and surrounding social, economic and environmental factors. Once understood, these relationships hold important implications for health promotion policymaking, research and professional practice (World Health Organization, 1986).

Health promotion has been defined as "the process of enabling people to increase control over, and to improve their health" (World Health

*Author for correspondence.
Organization, 1986). In turn, health promotion is not solely the responsibility of the health sector. To reach a state of well-being an individual or group must be able to identify and realize aspirations, to satisfy needs, and to cope with or change their environment. Key international documents such as the Ottawa Charter (World Health Organization, 1986) recognize that healthful environments are fundamental to human health. Creating a healthful environment means altering or adapting social, economic and physical surroundings in ways that not only preserve, but enhance health. Population health promotion programs and policies can support the creation of healthful environments. The most effective interventions are those based on an understanding of relationships among health behaviors or lifestyles within their social and environmental context (Green and Kreuter, 1991; Hyndman, 1993; Fitness Canada, 1993; Underwood et al., 1993; Quinney et al., 1994; National Cancer Institute, 1995; Frankish et al., 1996a,b).

This paper begins by identifying approaches to the conceptualization of "determinants of health", "leisure activities" and "active living". Next, relationships between determinants of health (gender, age, education, race, social support, place of residence, socioeconomic factors, occupation, health behaviors, activity choices and leisure constraints) and levels and patterns of active living are reviewed. Finally, relationships between determinants of health and active living are summarized with the context of an integrative framework: the precedeproceed model of health promotion planning and evaluation (Green and Kreuter, 1991, Fig. 1). While the precede model has its roots in clinical health education and health promotion, over the years its has been widely employed in consideration of diverse health issues. Its use in the present context serves to highlight the need to link the historically, individual-focussed literature on physical activity/ active living with the emerging recognition that sociocultural and structural determinants play a key role in influencing a wide range of activities of daily life. 


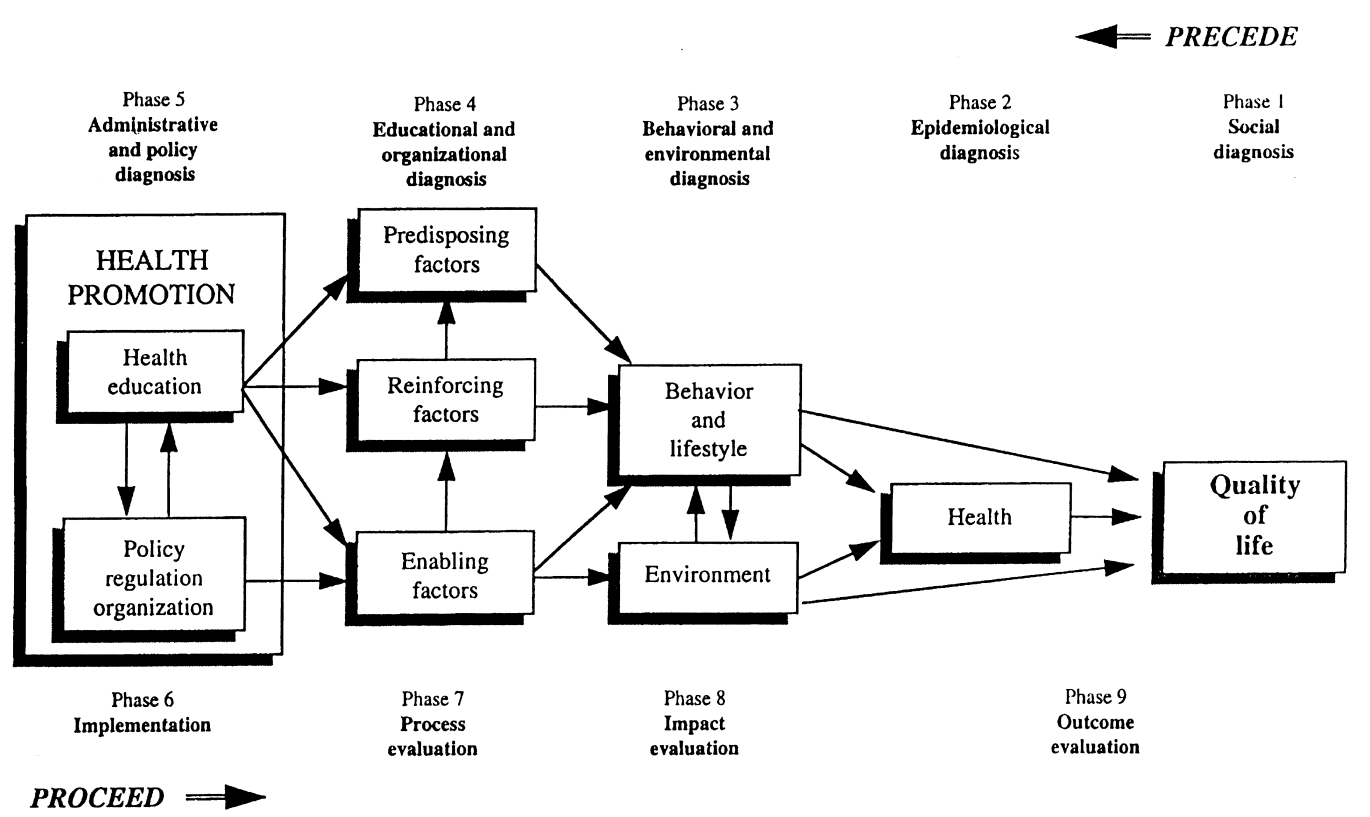

Fig. 1. Precede-proceed model of health promotion planning.

\section{CONCEPTUALIZATION OF DETERMINANTS OF HEALTH}

There exists a range of candidates for determinants of health (Evans et al., 1994; Wigle et al., 1995), many of which can be termed life circumstances (e.g., nutrition, shelter, social support). Such external factors are linked to individual-specific determinants (genetic endowment). Intra-individual and interpersonal/environment factors related to active living interact and manifest in many ways. These include one's life history of attempts to maintain fitness, individual responses to the demands or reinforcement(s) of others which impede, enable or promote one's attempts to be active.

Factors determining health go well beyond the illness-care system (Ontario Premier's Council on Health Strategy, 1991; Evans et al., 1994; Ontario Public Health Association, 1994; Sundquist, 1995; Wigle et al., 1995). When health is viewed as being more than strictly derived from individual (lifestyle) choice then clear links between health and life circumstances emerge (Milio, 1986; Hertzman et al., 1990; Osipow and Fitzgerald, 1993; O’Neill, 1993; Hertzman et al., 1994).

Determinants of health have been variously conceptualized as involving domains or lists of specific determinants (Ontario Premier's Council on Health Strategy, 1991; Ontario Public Health Association, 1994). These domains (Ontario Public Health Association, 1994) include: social environment, physical environment, individual responses and productivity/wealth. Typically identified determinants (Ontario Public Health Association, 1994) include: family experience, self-esteem, sense of control, employment, socioeconomic status, education, social support, access/geography, recreation, public policy and marginalization based on language, gen- der, race, income. Evans, Hertzman and their colleagues (Evans et al., 1994; Hertzman et al., 1990, 1994) provide a useful conceptual framework for determinants of health that includes three axes: stages of life cycle, subpopulation partitions and sources of homogeneity. Lifestyle and health behaviors vary with one's position in a social hierarchy (associated with income and social class) but not exclusively (Hertzman et al., 1990; Osler, 1993; Dean and Concha Perez-Hoyos, 1995; Martin et al., 1995). Life circumstances, in combination or individually, may influence an individual's desire, ability, and likelihood of taking part in active living, and therefore to affect their health status.

It must be noted that the conceptualization of "determinants of health" remains problematic. Many categories overlap and the quality of evidence regarding the relationships between specific determinants and specific aspects of health is quite uneven. In the present paper, the terms "determinants of health" and "conditions of living" are taken to be practically synonymous to refer to the broad range of factors influencing a person's health. Our review includes: gender, age, education, race, social support, place of residence, socioeconomic factors, work/occupation, health behaviors, and active living choices and constraints as determinants of health. We recognize that the definitions of such terms and views on their relations to active living, health and quality-of-life are not value-free. Recent authors have raised legitimate concerns and questions regarding the need to consider health inequity issues in any discussion of the role of sociocultural determinants of health (Coburn and Poland, 1996). 


\section{CONCEPTUALIZATION OF LEISURE ACTIVITIES}

One of the more difficult issues associated with a study of the relationships between active living and determinants of health is adequate measurement and categorization of active living and of leisure and recreational activities (Richardson et al., 1994; Canon et al., 1995; Richardson et al., 1995; Booth et al., 1996). Two major approaches to conceptualization of leisure and recreational activities exist: descriptive and psychometric. The conceptualization of active living developed by Health Canada will be discussed separately below.

The descriptive approach is typified by the taxonomy of leisure activities developed by Tinsley and Eldredge (1995). Their taxonomy includes 11 categories: agency, novelty, belongingness, service, sensual enjoyment, cognitive stimulation, selfexpression, creativity, competition, vicarious competition and relaxation. In a similar fashion. Beatty and Jeon (1994) proposed five leisure dimensions: outdoor-nature, passive-in-home, sports action, social entertainment and aesthetic-intellectual.

The psychometric approach is characterized by the use of self-report, paper-and-pencil measures (Walker et al., 1987; Cardinal, 1993; Ellis and Witt, 1994; Cardinal, 1995). For example, Ellis and Witt (1994) recently developed the leisure diagnostic battery, which examined perceived freedom and satisfaction with leisure activities. Similarly, the healthpromoting lifestyle profile (Walker et al., 1987) attempts to measure self-actualization, health responsibility and exercise as elements of a healthful lifestyle.

Neither the "descriptive" nor the "psychometric" approach have proved sufficient or satisfactory in the conceptualization or measurement of leisure/ physical activities. The reasons for existing measurement problems are multiple and complex. They lie in challenges in selecting relevant items, articulating a "metric" for specific measures, and in the repeatedly reported weak associations between participation in activities (behaviors) and quality-of-life.

\section{CONCEPTUALIZATION OF ACTIVE LIVING}

In 1986, the Canadian Summit on Fitness defined fitness as "a state of total well-being of the individual - physical, mental, spiritual, emotional and social". This definition of fitness led to the concept of "active living" being developed by Health Canada (Health and Welfare Canada, 1991). The notion of active living represents a shift away from the view of fitness and physical activity as simply prescriptive, expert-driven, mechanical movement (Bouchard and Shephard, in press; Stewart, 1995).

Active living acknowledges that "participation involves the whole person, body, mind and spirit; is part of a dynamic life, in which individuals and environments continuously interrelate and affect each other, and is subjective in nature, its meaning relative to each person' (Active Living Canada, 1994; Bercovitz and Skinner, 1996). It is based on three principles: active living is individual, active living is social, and active living is inclusive.

Recently, Bercovitz and Skinner (1996) identified assumptions and limitations concerning the meaning of active living. These included: operationalization, measurement, government turf battles, topdown pressure, fear of replacement/role loss, perceived lack of expertise and discomfort associated with the perception of active living as a political construct. Clarification and communication of active living as a useful concept requires the building of a research base and enhanced governmental and organizational support. Many people experience significant challenges in attempting to create cooperative, innovative approaches to active living that are conducive to their well-being and qualityof-life (Frankish and Green, 1994; Whittemore, 1994).

In summary, increasing numbers of individuals have come to appreciate the benefits of active living. This development is reflected in positive societal responses to campaigns (e.g., PARTICIPaction in Canada), growth of the fitness industry, and a rise in exercise participation rates over the past 3 decades (that may have plateaued or even started to decline). The relevance of active living has spread among fitness, recreation and health professionals, yet much remains to be done in policy, research and practice linking active living and health in the context of the determinants of health.

The following sections review the relationships between active living and specific determinants of health. Information regarding the prevalence, patterns and types of active living across different life circumstances and determinants of health are described. The use of the terms recreation, leisure, physical activity, exercise and active living reflects their use by original authors. Otherwise, they are used interchangeably. The limitations of given measures and/or bodies of literature are not the direct focus of this paper. Rather, such limitations are noted and potential opportunities for moving towards a more integrated approach to consideration of active living - determinants of health relations are identified.

\section{GENDER DIFFERENCES AND ACTIVE LIVING}

Researchers are attempting to understand gender differences in leisure and recreation, the meaning of leisure among men and women, and gender-related constraints on activity (Hawkes and Holm, 1993; Dean and Concha Perez-Hoyos, 1995; Hultsman, 1995, Mcdermott, 1996, Reeves and Szafran, 1996). For example, men are more likely to have a sense of control over being active on a regular basis. 
Men rate regular activity as important to their health more often than women, and they report receiving more encouragement from others (Yoshida et al., 1988; Woodward et al., 1989; Stephens and Craig, 1990; Del-Rey, 1991; Henderson and Dialeschki, 1991; Lenskyj, 1991; King et al., 1992; Hall et al., 1992; Muraki et al., 1993; Statistics Canada, 1994, 1995; Felton and Parsons, 1994; Bonen and Shaw, 1995; Garcia et al., 1995). Gender differences in sedentariness (Crespo et al., 1996) continue to contribute to disturbingly high levels of physical inactivity.

Women's and men's leisure opportunities and activities may be bounded by similar constraints such as paid employment, parenthood, poverty and loneliness, but these factors appear to impinge in different ways and to a greater or lesser extent as a reflection of contemporary gender roles (Woodward et al., 1989; Yeager and Macera, 1994). Some researchers (Woodward et al., 1989; Henderson and Dialeschki, 1991; Muraki et al., 1993; Garcia et al., 1995) have suggested that women may believe that they have little or no right to leisure and this belief may place severe limitations on their construction of time for leisure and their attitudes towards leisure. The role of structural/contextual factors in relation to gender differences and active living have not been adequately addressed in much of the epidemiologic, quantitative literature on physical and leisure activities.

Recently, Harrington and Dawson (1995) used Canadian data to examine women's leisure meaning systems, their experiences of leisure, and constraints to their experience of leisure. Their findings showed that women do not, regardless of their labor force participation, subscribe to the view that leisure is free time. Similarly, Jackson and Henderson (1995) reported that women are more constrained in their leisure than men. Contextual factors including age, income and family structure also serve as mediating factors that alter, reinforce or alleviate gender-related leisure constraints. A meta-analysis conducted by Lirgg (1991) found gender differences in self-confidence in activity competitiveness. In a similar vein, Freysinger and colleagues (Freysinger and Flannery, 1992; Freysinger, 1995) demonstrated that men and women differ in the types (e.g., level of competitiveness, formal/informal) of leisure activities they pursue, and that such differences vary across age groups.

In summary, although the patterns of active living in North America have changed significantly over the past several decades, there is evidence that gender differences remain. While women are generally as active as men between ages 25-64 years, men in the oldest and youngest age groups are more active (Ainsworth et al., 1993). There is strong evidence suggesting that women's ability to engage in active living is constrained by both social norms and structural factors. Gender differences in active living - determinants of health are a microcosmic reflection of the relative poverty, lower social mobility and powerlessness of women. Much remains to be done in describing and developing adequate models of such interrelations.

\section{AGE DIFFERENCES AND ACTIVE LIVING}

Age is a biological variable; it is also a psychological, socio-cultural and historical one that holds significance for the prevalence and patterns of active living. Research on the meaning and patterns of leisure, while taking account of gender, has not adequately situated leisure within the context of age (Greendale et al., 1996; Lissner et al., 1996; Melillo et al., 1996; Mills et al., 1996; Bungum and Vincent, 1997). Social and economic demands faced by specific age-groups (Rudman, 1989; Jonsson and Rosenbaum, 1993; Blanksby et al., 1996) vary over the lifecycle. There are changes both in potency and composition of age - active living - determinants of health relationships. Age influences one's decision to be involved in activities, and where involvement occurs. Over time, perceived benefits and restraints associated with activity change (Rudman, 1989).

The literature supports the notion that there is a general decline in physical activity participation and adherence from younger to older ages (Health and Welfare Canada, 1988; Stephens and Craig, 1990; Hall et al., 1992; King et al., 1992; Anderssen et al., 1996; Fletcher and Hirdes, 1996). This decline is especially steep between 15-24 years. Secular (cohort) trends indicating a general decline in physical activity have also recently been found. For example, the CARDIA study indicated a decrease in mean physical activity of approximately $30 \%$ in each race (black/white) by gender group across recent years (Anderssen et al., 1996; Liu et al., 1996). It must also be noted that age group differences are confounded with gender and race effects (Folsom et al., 1991). In turn, individual-specific characteristics (and choices) are nested within the larger sociocultural context and societal structures (AdamsCampbell et al., 1990; Wolf et al., 1993).

The pattern of decreased participation with aging is more pronounced among females, the less welleducated, those with lower incomes and those who live in rural areas. Participation rates reverse for those aged $65+$ years. Seniors are most likely to meet age-specific criteria for regular activity and three-quarters of seniors are regular walkers (Thibault, 1980; Health and Welfare Canada, 1989; Sallis et al., 1989; Health Canada, 1991; Duncan et al., 1995a,b,c; Lombard et al., 1995; Siegel et al., 1995; Gillis and Hirdes, 1996; Strawbridge et al., 1996; Verbrugge et al., 1996; Yusuf et al., 1996). For example, Duncan et al. (1995a,b,c) found that mall-walking among seniors was related to social competence, social interactions and cognitive vari- 
ables. Notably, structured activities such as those which require schedules, coaches, competition and formal organization become less common with age, while the popularity of activities such as gardening and walking increases with age (Health Canada, 1991).

Freysinger (Freysinger and Flannery, 1992; Freysinger, 1995) recently explored the meaning of leisure among women and men in midlife, and if and how gender and age distinguished leisure meanings. Results indicated that leisure is both a context for age-related development and an expression of development. Mid-life leisure is multi-dimensional and reflects elements of need for novelty, disengagement, agency and affiliation. These variations reflect the reality that different individuals are variously exposed to societal structures and opportunities for active living as they develop through the life span.

Life transitions also have particular relevance and impact on health and its relationships to active living. For example, data from the Kaiser permanent study (Midanik et al., 1995) show that retirees report lower levels of stress and are more likely to engage in regular exercise than the actively employed. These findings underscore the importance of assessing positive benefits associated with life transitions such as retirement. They also raise questions as to how programs and policies can be put in place to support and facilitate active living across different age groups (Cook and Settersten, 1995; Richardson and Kilty, 1995).

\section{EDUCATION AND ACTIVE LIVING}

Evidence exists of a direct relationship between education and the probability of being active (Stephens and Craig, 1990; King et al., 1992; Statistics Canada, 1994). Those with a college or university education are most likely to be active and least likely to be sedentary. Persons who did not finish high school are most likely to be sedentary (Stephens and Craig, 1990; King et al., 1992). These patterns are due to the amount of time devoted to physical activity by more educated persons, rather than to a choice of higher intensity activities (King et al., 1992; Statistics Canada, 1994). Walking, swimming, and bicycling are more popular among those who are highly educated, whereas gardening and dancing appear consistently popular across all education levels (Stephens and Craig, 1990; Strawbridge et al., 1996). Sage (1986) also reported positive relationships between interscholastic sports and academic achievement, even when social variables were controlled. The higher rates of participation among more educated persons is confounded with their greater relative wealth, mobility and often more developed social networks.

In a recent review, Ross and Wu (1995) concluded that the positive association between education and health is well established, but that explanations (e.g., the impact of other determinants of health) for the relationships are not. Explanations fall into 3 categories: (1) work/economic conditions, (2) social-psychological resources, and (3) healthful lifestyle. The well-educated are more likely to work full-time, to have subjectively fulfilling and rewarding jobs, high incomes and fewer economic hardships. Full-time work, fulfilling work, high income and absence of economic hardship in turn significantly improves health. Second, well-educated individuals report a greater sense of control over their lives and their health and higher levels of social support. Sense of control and to a lesser extent social support are associated with good health. Third, the well-educated are less likely to smoke, more likely to exercise, to get health checkups and to drink moderately. None of the three available explanations is wholly adequate. High educational attainment appears to improve health directly, as well as improving health indirectly through and economic conditions, social-psychological resources and healthful lifestyle, topic of structural barriers. It is very important to note the impact of the level of mechanization within the individual's life and culture (Pollard and Storper, 1996; Adler and Borys, 1995). Clearly, the mechanization of North American society and the emerging information revolution have had (and will have) profound impact on patterns of transportation, work activities and modes of accomplishing daily tasks. In turn, such factors are mediated and moderated by the determinants of health and play an influential in the patterns of active living displayed by specific individuals or groups. Active living is increasingly "built-out" of our work and daily lives.

\section{RACE AND ACTIVE LIVING}

The conceptualization and measurement of relations between race and specific social or behavioral phenomena is problematic. More specifically, the linking of race with health behaviors within or across racial groups remains highly challenging (Alicea and Kessel, 1997; Toth and Brown, 1997). There exists little evidence regarding race-leisure relationships.

Halpern (1993) suggests that it is experience at the local, rather than the national level, that is critical to specific racial groups. For nonminority groups, positive effects seen at the local level appear to be related to the reduced exposure to prejudice and the increased social support offered by being a member of a majority group. The effects of race and/or ethnicity on active living are also confounded with age and socioeconomic variables such as education and income (Yoshida et al., 1988; Bode and Shephard, 1993; Philipp, 1994, 1995; Bode and Shephard, 1995; Broman, 1995; Clark, 1995; Kelley, 1995; Macera et al., 1995; Shinew et al., 1995). Clark (1995) found for example that the 
majority of racial variation in physical activity among older adults was accounted for by racial differences in educational attainment.

Many recent models of leisure constraints appear to overlook or disregard race despite its continuing importance to a wide variety of interpersonal behaviors. Philipp (1994, 1995) investigated relationships between race and measures of leisure constraint: appeal and comfort. Significant differences between African and European Americans were found in how identical activities were rated for appeal and comfort. Felton et al. (1997) recently reported that black and white college women had similar definitions of health, valued health to the same extent, and levels of exercise despite the fact that black women also reported social supports for active living.

Based on interest-group theory of class identification, it can be hypothesized that members of specific racial groups who define themselves similarly in terms of social class will exhibit similar leisure preferences. Floyd and Shinew (1994) found that middle class African Americans and whites exhibited similar leisure preferences. Patterns of leisure tended to diverge among the poor or the working class. However, Shinew et al. (1995) suggest that black-white differences in leisure preferences derive mainly from female-specific differences. Evidence exists that African American women are less active than whites (Yoshida et al., 1988; Bild et al., 1993; Yeager et al., 1993). Race-related gender differences also exist in need to excel (Bild et al., 1993). Broman (1995) demonstrated a link between leisure-time activity and efficacy cognitions related to health across racial groups. Leisuretime exercise was predicted by sense of efficacy that in turn was predicted by a general sense of mastery. Interestingly, the highly educated among both races were least likely to believe in the efficacy of exercise as a preventive health behavior. There is also some evidence that leisure-related activities in non-Whites may vary as a function of the degree of acculturation to White North American culture (Bode and Shephard, 1993, 1995).

In summary, evidence supports the existence of inter-racial differences in leisure-time activities, particularly among women. Race-leisure relationships are confounded with other determinants of health such as education, place of residence, social class and income. Any discussion of race-behavior relations must be cognizant of avoiding a "victimblaming" stances and fully recognize the profound influences of power, gender, education and income and their impact on active living.

\section{SOCIAL SUPPORT AND ACTIVE LIVING}

Social support and social relationships are key aspects of a person's life circumstances, major influences on health and well-being and important fac- tors in the development and maintenance of active living (Sage, 1986; Weyerer and Kupfer, 1994). There is evidence that despite the connection between social support and participation in vigorous activity, few people are encouraged by others to be active. Encouragement is most likely to come from within the family (Sallis et al., 1989; Stephens and Craig, 1990; Wankel, 1993; Fink and Wild, 1995; Anderssen et al., 1996). Lack of encouragement from one's physician is associated with reducing an activity regimen. Having an active spouse is an important form of encouragement (Sallis et al., 1989; Fink and Wild, 1995).

Sallis et al. (1989) reported that modelling and friend support influence active living habits. There is a strong tendency for people with active friends to be active themselves. People who are married to active individuals are $20 \%$ more likely to exercise regularly than people with sedentary spouses; those who describe most or all of their friends as active are $41 \%$ more likely to be regularly active themselves than people who have no active friends (Janzen and Cousins, 1995; Stephens and Craig, 1990). The relative influence of various groups (e.g., peers, family, spouse) on active living appears to vary across the life cycle (Sage, 1986; Ashford et al., 1993; Caldwell and Smith, 1995; Janzen and Cousins, 1995; Unger and Johnson, 1995; Daley and Parfitt, 1996). Social support may also be especially important for women. Wankel (1993) found that $62 \%$ of women vs only $26 \%$ reported exercising with a friend. Membership in health clubs also appears to facilitate active living (Ashford et al., 1993; Unger and Johnson, 1995; Daley and Parfitt, 1996). There are many possible reasons for the apparent connection between active living and social relationships and support. Active living may provide a vehicle for identification with and commitment to a particular group, social reinforcement and competitive stimulation (Wankel, 1993; Weyerer and Kupfer, 1994; Caldwell and Smith, 1995).

\section{PLACE OF RESIDENCE AND ACTIVE LIVING}

Few studies have described physical activity in different geographic communities and there appear to be few differences between communities of different sizes in the proportion of their populations classified as active (Stephens and Craig, 1990). There is, however, a modest increase in leisure time spent on activity as community size increases, as well as modest differences in activity choices (Health and Welfare Canada, 1988; Stephens and Craig, 1990; Hall et al., 1992).

Recently, Eaton et al. (1994) described the frequency, types and correlates of physical activity among adults living in a rural US county. Walking was the most popular activity and increased with 
age. In contrast, vigorous and team-related activities generally declined with age.

Individuals living in rural or remote areas may experience unique economic and social factors impinging on their opportunities and ability to engage in active living (Active Living Canada, 1994). Such barriers or challenges to active living may also have the greatest impact on women and children (Bushy, 1993; Eaton et al., 1994; Horne, 1994; Trost et al., 1996; Johnson et al., 1997). Horne (1994) combined the testing of social psychological theory with the practical concern of gathering information for social marketing of active living. Among rural homemakers, intentions, selfefficacy and beliefs related to barriers and social support discriminated active from inactive homemakers. For active homemakers, only attitude and self-efficacy predicted future intentions. Similarly, studies of physical activity among rural children indicate gender-related differences in self-confidence for overcoming barriers to activity (Trost et al., 1996).

\section{SOCIOECONOMIC FACTORS AND ACTIVE LIVING}

Socioeconomic status has a major effect not only on the relative health of groups within a population, but on the health of the "same" population at different points in time. Socioeconomic status has been represented by grouping individuals according to income, occupation or education. A number of studies have found gradients in life and health expectancy across such groups. Such gradients have persisted despite policy initiatives aimed at reducing them (Hertzman et al., 1990; Hertzman et al., 1994; Wigle et al., 1995).

Long-standing evidence suggests that persons with higher incomes, education and occupational (particularly the elderly) attainment engage in more active, diverse and intellectually demanding activities (Havighurst, 1974; Bynum et al., 1978; Lawton et al., 1982; Woodward et al., 1989; Anderssen and Wold, 1992). The same people often have the money, knowledge, organizational resources and flexible schedules to run sports organizations and to engage in active living (Hall et al., 1992; King et al., 1992).

Recent studies provide data concerning physical activity and/or leisure participation among minority and/or low-income persons (Ford et al., 1991; Bild et al., 1993; Bode and Shephard, 1993; Yeager et al., 1993; Lewis et al., 1993a,b; Bode and Shephard, 1995; Chepyatorthomson, 1995; Macera et al., 1995; Crespo et al., 1996; Paraschak, 1997). Studies typically use community based surveys in which the majority of respondents are young adult (AfricanAmerican) women. (Ford et al., 1991; Lewis et al., 1993a,b; Chepyatorthomson, 1995). Lewis et al. (1993a), Lewis et al. (1993b) found that $30 \%$ of low-income respondents reported no participation in any of 13 listed activities during the previous year. Persons who were young and male were more likely to have high activity levels.

Ford et al. (1991) studied physical activity during leisure, household activities or work among low socio-economic status men and women. Lower SES women were least active, while high SES women were most active. Higher SES men were also more active than their lower SES counterparts. High SES women spent considerably more time each week involved in leisure, household and job-related activities than low SES women.

In a similar study, Siegel et al. (1995) studied leisure-time activity among respondents to the 1990 Behavioral Risk Factor Surveillance System Survey. The percentages of low income, unemployed and obese persons who engaged in leisure-time physical activity were lower than that of the total population. This finding is consistent with other studies of similar populations (Fox and Dirkin, 1989; Ford et al., 1991; Lewis et al., 1993a,b; Lombard et al., 1995). In contrast, the prevalence of walking for exercise among these "sedentary" groups was similar to that of the general population $(35 \%)$.

Differences in patterns of active living related to socioeconomic factors have also been found in younger age groups. Among children, participation in organized sports cuts across all socioeconomic strata. Some sports are over-represented with children from upper-middle class families (Sage, 1986; Blanksby et al., 1996). A positive relationship exists between parental encouragement, activity participation and involvement in sports for both males and females (Sage, 1986). Parents significantly influence their children's leisure choices and behaviors through their own attitudes and modelling.

\section{WORK/OCCUPATION AND ACTIVE LIVING}

Occupation and work-related factors are closely related to other determinants of health (e.g., education, age, smoking and obesity) and are associated with varying levels of activity (Sallis et al., 1989; King et al., 1992; Gallo et al., 1995; Marino et al., 1995). A person's occupation and/or source of income may be a catalyst for active living. It may also serve to constrain their ability to take part in leisure activities (Shephard and Bouchard, 1994). Gender is strongly related to work and occupation.

Generally, homemakers and clerical/sales employees are the least likely to be active. (Women are disproportionately over-represented in these categories). Homemakers are more likely than others to engage in casually organized activities. Retirees are second to students in proportion of who is active (Stephens and Craig, 1990). Hall et al. (1992) reported that those not in the paid workforce (i.e. homemakers, retirees, the unemployed and the disabled) are inactive in "sports", but may be active in other activities such as walking, swimming, and 
gardening. Conversely, salaried professionals and managers with good educations and high incomes tend to engage in sports which require a relatively greater amount of money, such as downhill skiing, indoor tennis, squash, windsurfing, golf, sailing and equestrian. This is due to the amount of money required to participate in such activities, and is also due to the considerable professional autonomy provided by these occupations. The aforementioned sports also involve extensive preparation and training (Hall et al., 1992; Hoen, 1992). Blue-collar and white-collar men tend to be involved in activities which provide a social setting, such as bowling, baseball, softball, hockey and fishing (Hall et al., 1992). Working class women display little or no interest in sport. This is likely due to barriers such as childcare, transportation and lack of money (Hall et al., 1992).

The relationship between active living and job-related strain has been explored (Ormel et al., 1989; Brown, 1991; Jex et al., 1991). Jex et al. (1991) found exercise was weakly related to measures of physical strain (sick days and doctor visits) and psychological strain (job satisfaction and turnover intent). In a following study, which employed more specific measures of exercise, and a more heterogeneous sample, exercise was weakly related to physical strain (doctor visits) but unrelated to psychological strain.

In summary, there is evidence of significant relationships between physical activity and occupation or work. The source(s) of such relationships remains unclear (King et al., 1992). Nonwork activities may also have significant relationships to occupational roles and life satisfaction (Cox and Montgomery, 1991). Although activity preferences tend to be gender-dependent, there is also evidence that different age groups tend to have similar levels of activity preferences (Branholm and Fugl-Meyer, 1994).

\section{ACTIVE LIVING AND OTHER HEALTH BEHAVIORS}

Poor lifestyle habits are associated with increased morbidity and mortality rates and cost billions of dollars annually (Millar and Stephens, 1993; Anonymous, 1996; Gillis and Hirdes, 1996). Leisure-time physical activities have been linked to, or are associated with other health behaviors (Sobal et al., 1992; Uitenbroek, 1993a,b; Duncan et al., 1995a,b,c; Pate et al., 1996; Shephard and Bouchard, 1996). Typically surveys indicate that the majority of North Americans (Palank, 1991) rate their health as excellent or very good. Interestingly, data on self-rated health do not correlate well with the practice of other health behaviors. Frequent exercisers are more likely to rate their health positively and to describe themselves as happy. However, a majority of individuals who exercise less than 3 times per week also consider their health to be very good or excellent despite engaging in limited physical activity.

Recently, Johnson et al. (1995) suggested that the available data on associations between leisure-time physical activity and other health behaviors are conflicting. They examined National Heart Foundation (Australia) 1989 Risk Factor Prevalence Survey data to analyze associations between leisure-time physical activity and other lifestyle health behavior. Analysis showed that participation in leisure-time physical activity, even when it was not vigorous, was weakly associated with not smoking, following a special diet and moderate consumption of alcohol. It was inversely associated with obesity. The authors concluded that these weak associations could influence health practices at a population level if the adoption of leisure activity promotes the adoption of other good health practices. Their confirmation of earlier findings of cross-sectional associations between activity and other positive health practices justifies prospective or experimental studies to determine behavioral response(s) of various subpopulations to adoption of leisure-time physical activity.

Health promoting behavior and life style changes are influenced by a host of internal and environment factors, including personality factors, health beliefs, and health attitudes (Rabinowitz et al., 1993; Williams, 1994). Participation in physical activity may act as an entry point to reflect on health behavior practices, creating a ripple effect to other areas of lifestyle behaviors.

\section{ACTIVE LIVING: CHOICES AND CONSTRAINTS}

According to many surveys (Health and Welfare Canada, 1988; Yoshida et al., 1988; Stephens and Craig, 1990; King et al., 1992; Rabinowitz et al., 1993; Williams, 1994; Bonen and Shaw, 1995), the most popular activities reported by North Americans are walking, gardening, swimming, bicycling, and dancing. All of these activities have little need for supervision or training, are low cost, are convenient, and can be done outdoors and/or with friends (Stephens and Craig, 1990).

Perceived or real barriers are an important factor in predicting a wide range of health behaviors (Yoshida et al., 1988), and such barriers negatively influence active living behavior (Sallis et al., 1989, 1996). Time constraints are the most frequently cited cause for not being more active (Health and Welfare Canada, 1988; Yoshida et al., 1988; Rudman, 1989; Stephens and Craig, 1990). Additional barriers most frequently associated with physical activity involvement are physical demands of activity, lack of motivation, perceived lack of access to a health and fitness facility, and a lack of social support from significant others (Rudman, 1989). 
Yoshida et al. (1988) differentiated between individual and structural barriers. Individual barriers are obstacles to active living which originate within the person. Examples include lack of energy, motivation, need and health reasons (injury and disability). Structural barriers are obstacles which originate outside the person, such as lack of time, cost/access, child care, family responsibilities, and household size.

The British health and lifestyle survey (Cox et al., 1993) indicated clear effects of the social environment as presenting challenges to active living and an impact on both physical and mental health. Cox et al. (1993) also detected an important change-related phenomenon. A deterioration in perceived levels of social support was strongly related to psychosocial health. The impact of changes varied significantly across age, gender and occupations. There were also clear gradients in participation in active leisure pursuits with higher rates both in urban vs rural areas, and in those from non-manual occupations vs those from manual occupations. These differences held across both genders. Results indicated that participation in "non-energetic" pastimes increased (1986-1993) across all age groups. However, those from the lower (manual) occupational groups were less likely to engage in either energetic or non-energetic activities.

\section{INTEGRATIVE FRAMEWORK FOR CONSIDERING ACTIVE LIVING AND THE DETERMINANTS OF HEALTH}

Numerous authors have attempted to portray and explain relationships among the various factors discussed in this paper. The most common approach is to employ what has been called a "biopsychosocial" model (Eisenberg, 1986; Duffy, 1988; Valois et al., 1988; Cutrona, 1990; Omodei and Wearing, 1990; Sonstroem et al., 1991; Dishman, 1991; Headey and Veenhoven, 1991; Anderssen and Wold, 1992; English and Hicks, 1992; Ezzy, 1993; Facione, 1993; Budd, 1993; Cardinal, 1993; Cheadle and Psaty, 1993; Coppa, 1993; Headey, 1993; Galbally and Burrows, 1993; Johnson and Ratner, 1993; RuffingRahal, 1993; Meek, 1993; Marcus and Simkin, 1994; Zanger and Groves, 1994; Anderson and Armstead, 1995; Appleby, 1995; Brown, 1995; Cardinal, 1995; Davidson and Strauss, 1995; Duncan et al., 1995a,b,c; Feeny et al., 1995; Haworth, 1995).

A useful model which accommodates many of the above models in a broader, heuristic planning approach is termed the Precede-Proceed model. The Precede model (Green and Kreuter, 1991) grows out of the science and practice of health promotion. The model can be used to describe active living determinants of health relationships and to elucidate causal pathways between active living program approaches and program effects or outcomes regarding determinants of health. The Precede model can be used together with available models and theories of behavior change and systems for assessing available evidence. It provides an overall framework for organizing models and theories of behavior change. Most importantly, precede facilitates the systematic planning, implementation and evaluation of potential programs and policies. Precede prompts users to articulate the underlying theoretical rationale for postulating links between or among specific determinants and active living.

\section{WHY THE PRECEDE MODEL?}

The Precede model has been widely applied in disease prevention and health promotion programs, and tested in research and evaluation projects. With over 600 published applications (and an equal number of unpublished applications) on a variety of health issues, the Precede model is by far the most widely tested and validated model for planning health promotion programs and policies.

The Precede model has its roots in health education and health promotion. As such, it may be viewed by some overly as "individualistic" and not giving enough consideration to the growing emphasis on the social and "structural complexity" of health (Luschen et al., 1996). Models such as the Precede model, while they need to be viewed with a critical eye and with appropriate consideration of extra-individual factors such as the social-cultural environment and structures are still useful. Precede provides a widely-tested framework for consideration of the broader determinants of health (as they relate to active living). It also provides a platform for linking the historically, individual-focussed literature on active living/physical activity with the emerging recognition that determinants of health such as education and income play a key role in influencing a wide range of activities of daily life.

Recent applications include: AIDS (Alteneder et al., 1992), smoking, (Polcyn et al., 1991), cancer (Michielutte et al., 1989), injury prevention (Gielen, 1992), medication education (Opdycke et al., 1992), mental health (Frankish et al., 1996a,b), suicide prevention (Frankish, 1994), asthma education (Green and Frankish, 1994), arthritis (Bartholomew et al., 1994), breast cancer (Earp et al., 1995), patient education (Jenny, 1993) and ecological models of health promotion (Richard et al., 1996). The model also provided the framework for the construction of Canada's health promotion survey (Health and Welfare Canada, 1988). Recently, the model was used to examine predictors of regular physical activity in participants in a Canadian health promotion program (Hill, 1996).

\section{OUTLINE FOR USE OF THE PRECEDE MODEL}

The multiple levels of the model are displayed. The steps in precede (the upper portion) are 
sequenced from right to left. Precede deals with issues related to health beginning with an analysis of social costs and quality of life issues (Phase 1) and continues through administrative and policy diagnosis (Phase 5). The (lower) portion of the model, from left to right, addresses issues related to implementation (Phase 6), process evaluation (Phase 7), impact or short-term evaluation (Phase 8) and long-term or outcome evaluation (Phase 9). The levels of evaluation correspond in reverse order to the levels of objectives delineated in the planning phases of Precede. The model guides the planning itself, implementation of intervention strategies and policies, selection or development and implementation of educational, organizational and political strategies for change; evaluation of change in factors predisposing, enabling or reinforcing behavioral or environmental risk factors; and extrapolation of impact to outcomes measured in terms of risk factors themselves, or in terms of health or quality of life. The model is comprehensive enough to encompass the full range of activities and outcomes that active living (health) programs or policies might attempt to address.

In summary, three possible mechanisms for relationships between active living and determinants of health can be suggested. First, the pre-existence of positive living conditions is associated with a greater propensity to active living. Second, there is evidence that active living may lead to changes or improvements in living conditions and determinants of health. A final likelihood is that relationships between determinants of health and active living are entwined with the influence of covariables such as mental health. Socio-demographic variables and specific risk factors have largely similar patterns of association with excellent health and with ill-health (Fuchs, 1996). The processes by which excellent health is generated probably have much in common with those that generate ill-health. Equally, it is obvious that our understanding of the determinants of health-illness relation is better than that of the relationships determinants of optimal health and well-being (Fuchs, 1996).

What is needed is a systematic approach to considering and integrating diverse theoretical approaches, weighing them against the available empirical evidence. Planning policies and programs need to based on a sound decision-making framework (Green and Kreuter, 1991; Frankish and Green, 1994; Mackenbach et al., 1994) which takes into account causal models of active living. Other key issues to be considered include the role of feminist perspectives in physical activity and active living (Woodward et al., 1989; Del-Rey, 1991; Henderson and Dialeschki, 1991; Freysinger and Flannery, 1992; Freysinger, 1995; Wright, 1996), the role of government in setting health goals and objectives that address the determinants of health (Health and Welfare Canada, 1991 Fitness Canada,
1993; Active Living Canada, 1994; Frankish et al., 1996a,b; Federal, Provincial and Territorial Advisory Committee on Population Health, 1996), the development of community-driven approaches to active living (Cheadle and Psaty, 1993; Collette et al., 1994; Frankish and Green, 1994; Quinney et al., 1994; Edwards, 1995; Wright, 1996) methodologic and analytic refinement of survey strategies (Health and Welfare Canada, 1988; Thomas and Graham, 1993; Statistics Canada, 1994; Statistics Canada, 1995; Crespo et al., 1996) and exploration of participatory approaches to research on the relationships between active living and determinants of health (Green et al., 1995).

\section{REFERENCES}

Active Living Canada (1994) Active Living Assembly Summary Report. Kent Consulting, Ltd., Ottawa, Ont.

Adams-Campbell, L., Washburn, R. and Haile, G. (1990) Physical activity, stress, and type A behavior in blacks. Journal of the National Medical Association 82, 701-705.

Adler, P. and Borys, B. (1995) A portrait of the relationship between work and mechanization in the US economy. International Journal of Human Factors in Manufacturing 5, 345-375.

Ainsworth, B., Richardson, M., Jacobs, D. and Leon, A. (1993) Gender differences in self-reported physical activity. Women in Sports and Physical Activity 2, 1-16.

Alicea, M. and Kessel, B. (1997) The socially awkward question - a simulation exercise for exploring ethnic and racial labels. Teaching Sociology 25, 65-71.

Alteneder, R., Price, J., Telljohann, S., Didion, J. and Locher, A. (1992) Using the PRECEDE model to determine junior high school students' knowledge, attitudes, and beliefs about AIDS. Journal of School Health 62, 464-470.

Anderson, N. and Armstead, C. (1995) Toward understanding the association of socioeconomic status and health: A new challenge for the biopsychosocial approach. Psychosomatic Medicine 57, 213-225.

Anderssen, N. and Wold, B. (1992) Parental and peer influences on leisure-time physical activity in young adolescents. Research Quarterly for Exercise and Sport 63, 341-348.

Anderssen, N., Jacobs, D., Sidney, S., Bild, D., Sternfeld, B., Slattery, M. L. and Hannan, P. (1996) Change and secular trends in physical activity patterns in young adults. American Journal of Epidemiology 143, 351-362.

Anonymous (1993) Prevalence of sedentary lifestyle Behavioral Risk Factor Surveillance System, United States. Morbidity and Mortality Weekly Report 42, 576-579.

Anonymous (1996) Physical activity and cardiovascular health. NIH Consensus Development Panel on Physical Activity and Cardiovascular Health. JAMA 276, 241246.

Appleby, J. (1995) Creating healthier communities: 25 pioneering models. Healthcare Forum Journal 38, 43-54.

Ashford, B., Biddle, S. and Goudas, M. (1993) Participation in community sports centres: Motives and predictors of enjoyment. Journal of Sports Sciences 11, 249-256.

Bartholomew, L., Koenning, L., Dahlquist and Barron, K. (1994) An educational needs assessment of children with juvenile rheumatoid arthritis. Arthritis Care and Research 7, 136-143. 
Beatty, S. and Jeon, J. (1994) A cross-national study of leisure activities. Journal of Cross-Cultural Psychology 25, 409-422.

Bercovitz, K. and Skinner, H. (1996) Active living - just a passing fad. Canadian Journal of Public Health 87, 275279.

Bild, D., Jacobs, D., Sidney, S., Haskell, W., Anderssen, N. and Oberman, A. (1993) Physical activity in young black and white women. CARDIA Study. Annals of Epidemiology 3, 636-644.

Bjorntorp, P. (1995) Evolution of the understanding of the role of exercise in obesity and its complications. International Journal of Obesity and Related Metabolic Disorders 19, S1-S4.

Blanksby, B., Anderson, M. and Douglas, G. (1996) Recreational patterns, body composition and socioeconomic status of Western Australian secondary school students. Annals of Human Biology 23, 101-112.

Bode, A. and Shephard, R. (1993) Acculturation and loss of fitness in the Inuit: The preventive role of active leisure. Arctic Medical Research 52, 107-112.

Bode, A. and Shephard, R. (1995) A comparison of physical fitness between Igloolik Inuit and Volochanka Nganasan. American Journal of Human Biology 7, 623630.

Bonen, A. and Shaw, S. (1995) Recreational exercise participation and aerobic fitness in men and women: Analysis of data from a national survey. Journal of Sports Sciences 13, 297-303.

Booth, M., Owen, N., Bauman, A. and Gore, C. (1996) Retest reliability of recall measures of physical activity in Australian adults. International Journal of Epidemiology 25, 153-159.

Bouchard, C. and Shephard, R. (in press) Physical activity, fitness and health: A model and key concepts. In Physical activity, fitness and health: A consensus on the current state of knowledge. eds. C. Bouchard, R. Shephard, T. Stephens, Human Kinetics Press, Champaign, Ill.

Branholm, I. and Fugl-Meyer, A. (1994) On non-work activity preferences: Relationships with occupational roles. Disability and Rehabilitation 16, 205-216.

Broman, C. (1995) Leisure-time physical activity in an African-American population. Journal of Behavioral Medicine 18, 341-353.

Brown, J. (1991) Staying fit and staying well: Physical fitness as a moderator of life stress. Journal of Personality and Social Psychology 60, 555-561.

Brown, V. (1995) The effects of poverty environments on elders' subjective well-being: A conceptual model. Gerontologist 35, 541-548.

Budd, K. (1993) Self-coherence: Theoretical considerations of a new concept. Archives of Psychiatric Nursing 7 , 361-368.

Bungum, T. and Vincent, M. (1997) Determinants of physical activity among female adolescents. American Journal of Preventive Medicine 13, 115-122.

Bushy, A. (1993) Rural women: Lifestyle and health status. Nursing Clinics of North America 28, 187-197.

Bynum, J., Cooper, B. and Acuff, F. (1978) Retirement orientation. Journal of Gerontology 33, 253-261.

Caldwell, L. and Smith, E. (1995) Health behaviour of leisure alienated youth. Society and Leisure 18, 143-156.

Caltabiano, M. (1995) Main and stress-moderating health benefits of leisure. Society and Leisure 18, 33-51.

Canon, F., Levol, B. and Duforez, F. (1995) Assessment of physical activity in daily life. Journal of Cardiovascular Pharmacology 25, S28-S34.

Cardinal, B. (1993) Reliability and validity of the lifestyle exercise inventory. Perceptual and Motor Skills 77, 1274.

Cardinal, B. (1995) Development and evaluation of stagematched written materials about lifestyle and structured physical activity. Perceptual and Motor Skills 80, 543546.

Cheadle, A. and Psaty, B. (1993) An empirical exploration of a conceptual model for community based health-promotion. International Quarterly of Community Health Education 613, 329-363.

Chepyatorthomson, J. (1995) Multicultural considerations in physical activity - an introduction. Quest 47, 1-6.

Clark, D. (1995) Racial and educational differences in physical activity among older adults. Gerontologist $\mathbf{3 5}$ $472-480$.

Coburn, D. and Poland, B. (1996) The CIAR vision of the determinants of health: A critique. Canadian Journal of Public Health 87(5), 308-310.

Collette, M., Godin, G., Bradet, R. and Gionet, N. (1994) Active living in communities: Understanding the intention to take up physical activity as an everyday way of life. Canadian Journal of Public Health 85, 418-421.

Cook, F. and Settersten, R. (1995) Expenditure patterns by age and income among mature adults: Does age matter? Gerontologist 35, 10-23.

Coppa, D. (1993) Chaos theory suggests a new paradigm for nursing science. Journal of Advanced Nursing 18, 985-989.

Cox, C. and Montgomery, A. (1991) Fitness and absenteeism among hospital workers. Clarifying the connection. AAOHN Journal 39, 189-198.

Cox, B., Huppert, F. and Whichelow, M. (1993) The health and lifestyle survey: Seven years on. Dartmouth Publishing, London.

Crespo, C., Keteyian, S., Heath, G. and Sempos, C. (1996) Leisure-time physical activity among US adults. Results from the Third National Health and Nutrition Examination Survey. Archives of Internal Medicine 156, 93-98.

Cutrona, C. (1990) Stress and social support: In search of optimal matching. Social support in social and clinical psychology. Journal of Social and Clinical Psychology 9, $3-14$

Daley, A. and Parfitt, G. (1996) Good health - is it worth it - mood states, physical well-being, job satisfaction and absenteeism in members and non-members of a British corporate health and fitness club. Journal of Occupational and Organizational Psychology 69, 121134.

Davidson, L. and Strauss, J. (1995) Beyond the biopsychosocial model: Integrating disorder, health, and recovery. Psychiatry: Interpersonal and Biological Processes 58, 44-55.

Dean, K. and Concha Perez-Hoyos, S. (1995) Research on lifestyles and health: Searching for meaning. Social Science and Medicine 41, 845.

Del-Rey, P. (1991) Women, physical activity and sport: Issues related to empowerment, In Proceedings of the Maccabiah-Wingate International Congress, Netanya, eds. G. Tenenbaum, and D. Eiger, pp. 68-72. Wingate Institute, The Emmanuel Gill Publishing House.

Dishman, R. (1991) Increasing and maintaining exercise and physical activity. Behaviour Therapy 22, 345-378.

Duffy, M. (1988) Health promotion in the family: Current findings and directives for nursing research. Journal of Advanced Nursing 13, 109-117.

Duncan, H., Travis, S. and Mcauley, W. (1995a) An emergent theoretical model for interventions encouraging physical activity (mall walking) among older adults. Journal of Applied Gerontology 14, 64-77.

Duncan, D., Boar, G., Nicholson, T., Wilson, R. and Higgins, W. (1995b) Health practices and mental health revisited. Psychological Reports 77, 205-206.

Duncan, B., Chambless, L., Schmidt, M., Szklo, M., Folsom, A., Carpenter, M. and Crouse, J. (1995c) Correlates of body fat distribution. Variation across categories of race, sex, and body mass in the atherosclero- 
sis risk in communities study. The atherosclerosis risk in communities (ARIC) study investigators. Annals of Epidemiology 5, 192-200.

Earp, J., Alpeter, M., Mayne, L., Viadro, C. and Omalley, M. (1995) The North Carolina breast cancer screening program - Foundations and design of a model for reaching older, minority, rural women. Breast Cancer Research and Treatment 35, 7-22.

Eaton, C., Nafziger, A., Strogatz, D. and Pearson, T. (1994) Self-reported physical activity in a rural county: A New York county health census. American Journal of Public Health 84, 29-32.

Edwards, P. (1995) Collective action: The community-driven approach to active living. Active Living Canada, Gloucester, Ont.

Eisenberg, L. (1986) Role of social factors in health and well being: Biopsychosocial model from a social perspective. Integrative Psychiatry 4, 8-9.

Ellis, G. and Witt, P. (1994) Perceived freedom in leisure and satisfaction. Leisure Sciences 16, 259-270.

English, J. and Hicks, B. (1992) A systems-in-transition paradigm for healthy communities. Canadian Journal of Public Health 83, 61-65.

Evans, R., Barer, M. and Marmor, T. (1994) Why are some people healthy and others not? Aldine de Gruyter, New York.

Ezzy, D. (1993) Unemployment and mental health: A critical review. Social Science and Medicine 37, 41-52.

Facione, N. (1993) The Triandis model for the study of health and illness behaviour: A social behaviour theory with sensitivity to diversity. Advances in Nursing Science 15(3), 49-58.

Federal, Provincial and Territorial Advisory Committee on Population Health (1996) Report on the Health of Canadians, Ottawa, Ont.

Feeny, D., Furlong, W., Boyle, M. and Torrance, G. (1995) Multi-attribute health status classification systems-health utilities index. Pharmacoeconomics 7, 490502.

Felton, G. and Parsons, M. (1994) Factors influencing physical activity in average-weight and overweight young women. Journal of Community Health Nursing 11, 109-119.

Felton, G., Parsons, M., Misener, T. and Oldaker, S. (1997) Health-promoting behaviors of black and white college women. Western Journal of Nursing Research 19, 654-666.

Fink, B. and Wild, K. (1995) Similarities in leisure interests-effects of selection and socialization in friendships. Journal of Social Psychology 135, 471-482.

Fitness Canada (1993) Minister's Steering Committee on Active Living Final Report. Ottawa, Ont.

Fletcher, P. and Hirdes, J. (1996) A longitudinal study of physical activity and self-rated health in Canadians over 55 years of age. Journal of Aging and Physical Activity 4, 136-150.

Floyd, M. and Shinew, K. (1994) Race, class, and leisure activity preferences: Marginality and ethnicity revisited. Journal of Leisure Research 26, 158-173.

Folsom, A., Caspersen, C., Taylor, H., Jacobs, D., Luepker, R., Gomez-Marin, O., Gillum, R. and Blackburn, H. (1985) Leisure-time physical activity and its relationship to coronary risk factors in a populationbased sample. The Minnesota Heart Survey. American Journal of Epidemiology 121, 570-579.

Folsom, A., Cook, T., Sprafka, J., Burke, G., Norsted, S. and Jacobs, D. (1991) Differences in leisuretime physical activity levels between blacks and whites in populationbased samples: The Minnesota Heart Survey. Journal of Behavioral Medicine 14, 1-9.

Folsom, A., Arnett, D., Hutchinson, R., Liao, F., Clegg, L. and Cooper, L. (1997) Physical activity and incidence of coronary heart disease in middle-aged men and women. Medicine and Science in Sports and Exercise 29, 901-909.

Ford, E., Merritt, R., Heath, G., Powell, K., Washburn, R., Kriska, A. and Haile, G. (1991) Physical activity behaviours in lower and higher socioeconomic status populations. American Journal of Epidemiology 133, $1246-1256$

Fox, K. and Dirkin, G. (1989) Psychological Orientation to Exercise in Obese Adults. North American Society for the Psychology of Sport and Physical Activity. Annual Meeting. Kent State University, Kent, OH, June 1-4.

Francis, K. (1996) Physical activity in the prevention of cardiovascular disease. Physical Therapy 76, 456-468.

Frankish, J. (1994) PRECEDE: A health promotion model for suicide prevention. Death Studies 18, 327340.

Frankish, C., Green, L. (1994) Organizational and community change as the scientific basis for disease prevention and health promotion policy. In Advances in Medical Sociology, ed. G. Albrecht, Volume IV, pp. 209-233. JAI Press, Greenwich, CT.

Frankish, J., Milligan, D. and Reid, C. (1996a) Active living and mental health: Their relations in the context of life circumstances and the determinants of health. Report for the Canadian Fitness and Lifestyle Research Institute and Health Canada, Ottawa, Ont.

Frankish, J., Green, L., Ratner, P., Chomik, T. and Larsen, C. (1996b) Health impact assessment as a tool for population health promotion and public policy. Report for Health Canada, Ottawa, Ont.

Frederick, C. and Shaw, S. (1995) Body image as leisure constraint. Leisure Sciences 17, 57-73.

Freysinger, V. (1995) The dialectics of leisure and development for women and men in mid-life-an interpretive study. Journal of Leisure Research 27, 61-84.

Freysinger, V. and Flannery, D. (1992) Women's leisure: Affiliation, self-determination, empowerment and resistance? Society and Leisure 15, 303-321.

Fries, J. (1996) Physical activity, the compression of morbidity, and the health of the elderly. Journal of the Royal Society of Medicine 89, 64-68.

Fuchs, R. (1996) Causal models of physical exercise participation. Journal of Applied Social Psychology 26, 1931-1960.

Galbally, R. and Burrows, G. (1993) Planning health promotion: A proposal for a health status model. Mental Health in Australia 5, 15-37.

Gallo, J., Marino, S., Ford, D. and Anthony, J. (1995) Filters on the pathway to mental health care. Psychological Medicine 25, 1149-1160.

Garcia, A., Broda, M., Frenn, M., Coviak, C., Pender, N. and Ronis, D. (1995) Gender and developmental differences in exercise beliefs among youth and prediction of their exercise behaviour. Journal of School Health 65, 213-219.

Gielen, A. (1992) Health education and injury control: Integrating approaches. Health Education Quarterly 19, 203-218.

Gillis, K. and Hirdes, J. (1996) The quality of implications of health practices among older adults. Canadian Journal on Aging 15, 299-314.

Green, L. and Kreuter, M. (1991) Health promotion planning: An educational and environmental approach. Mayfield Publishing, Mountain View, CA.

Green, L. and Frankish, C. (1994) Theories and principles of health education applied to asthma. Chest 106, S219S230.

Green, L., George, A., Daniel, M., Frankish, J., Herbert, C., Bowie, W. and O'Neill, M. (1995) Participatory Research in Health Promotion, Royal Society of Canada, Ottawa.

Greendale, G., Bodindunn, L., Ingles, S., Haile, R. and Barrett-Connor, E. (1996) Leisure, home, and occu- 
pational physical activity and cardiovascular risk factors in postmenopausal women - the Postmenopausal Estrogen Intervention Study. Archives of Internal Medicine 156, 418-424.

Hall, A., Slack, T., Smith, G. and Whitson, D. (1992) Sport in Canadian Society. McClelland and Stewart Inc., Toronto.

Halpern, D. (1993) Minorities and mental health. Social Science and Medicine 36, 597-607.

Harrington, M. and Dawson, D. (1995) Women's labour force participation, perceptions of leisure and constraints to enjoyment of leisure. Journal of Leisure Research 27, 4-24.

Havighurst, R. (1974) Leisure and lifestyle. In Concepts of leisure, ed. J. Murphy. Prentice-Hall, Englewood Cliffs.

Hawkes, J. and Holm, K. (1993) Gender differences in exercise determinants. Nursing Research 42, 166-172.

Haworth, J. (1995) Leisure and categorical models of mental health. Society and Leisure 18, 53-66.

Headey, B. (1993) An economic model of subjective wellbeing: Integrating economic and psychological theories. Social Indicators Research 28, 97-116.

Headey, B. and Veenhoven, R. (1991) Top-down vs bottom-up theories of subjective well-being. Social Indicators Research 24, 81-100.

Health and Welfare Canada (1988) Canada's Health Promotion Survey, Ottawa.

Health and Welfare Canada (1989) The active health report on fitness, nutrition and safety, Ottawa.

Health and Welfare Canada (1991) Active living: A conceptual overview, Ottawa.

Health Canada (1991) Emotional balance: Results of the Bradburn Affect Balance Scale in the 1991 General Social Survey, Ottawa.

Heath, G. and Smith, J. (1994) Physical activity patterns among adults in Georgia: Results from the 1990 Behavioral Risk Factor Surveillance System. Southern Medical Journal 87, 435-439.

Henderson, K. and Dialeschki, M. (1991) A sense of entitlement to leisure as constraint and empowerment for women. Leisure Sciences 13, 51-65.

Hertzman, C., Frank, J. and Evans, R. (1990) Heterogeneities in health status, Canadian Institute for Advanced Research, \#3C. Toronto.

Hertzman, C., Frank, J. and Evans, R. (1994) Heterogeneities in health status and the determinants of health of population health. In Why are some people healthy and others not? eds. R. Evans, M. Barer and T. Marmor. Aldine de Gruyter, New York.

Hill, A. (1996) Predictors of regular physical activity in participants in a Canadian health promotion program. Canadian Journal of Nursing Research 28, 119-141.

Hoen, P. (1992) The effects of continuity of leisure, informal social support, and self-esteem on the psychological well-being of aged, physically disabled persons. University Microfilms International, Ann Arbor, MI.

Horne, T. (1994) Predictors of physical activity intentions and behaviour for rural homemakers. Canadian Journal of Public Health 85, 132-135.

Hultsman, W. (1995) Recognizing patterns of leisure constraints. Journal of Leisure Research 27, 228-244.

Hyndman, B. (1993) The use of social science theory to develop health promotion programs. Paper prepared by the Centre for Health Promotion, University of Toronto.

Jackson, E. and Henderson, K. (1995) Gender-based analysis of leisure constraints. Leisure Sciences 17, 3151.

Janzen, W. and Cousins, S. (1995) Marriage, women and physical activity. Journal of Women and Aging 7, 55-70.

Jenny, J. (1993) A future perspective on patient/health education in Canada. Journal of Advanced Nursing 18, 1408-1414.
Jex, S., Spector, P., Gudanowski, D. and Newman, R. (1991) Relations between exercise and employee responses to work stressors: A summary of two studies. Journal of Social Behaviour and Personality 6, 425-443.

Johnson, J. and Ratner, P. (1993) An exploration of Pender's Health Promotion Model using LISREL. Nursing Research 42, 132-138.

Jonsson, B. and Rosenbaum, J. (1993) Health economics of depression. Chichester, England; Wiley, New York.

Johnson, N., Boyle, C. and Heller, R. (1995) Leisure-time physical activity and other health behaviours: Are they related? Australian Journal of Public Health 19, 69-75.

Johnson, C., Horan, P. and Pepper, W. (1997) Race, rural residence, and wildland visitation examining the influence of sociocultural meaning. Rural Sociology 62, 89110.

Kelley, G. (1995) Gender differences in the physical activity levels of young African-American adults. Journal of the National Medical Association 87, 545-548.

King, A., Blair, S., Bild, D., Dishman, R., Dubbert, P., Marcus, B., Oldridge, N., Paffenbarger, R. Jr., Powell, K. and Yeager, K. (1992) Determinants of physical activity and interventions in adults. Medicine and Science in Sports and Exercise 24, S221-S236.

Lawton, M., Moss, M. and Fulcomer (1982) Determinants of Activities of Older People, Philadelphia Geriatric Center, Philadelphia.

Lenskyj, H. (1991) Women, Sport and Physical ActivityResearch and Bibliography, Minister of Supply and Services Canada.

Lewis, C., Raczynski, J., Heath, G., Levinson, R., Hilyer, J. and Cutter, G. (1993a) Promoting physical activity in low-income African-American communities. Ethnicity and Disease 3, 106-118.

Lewis, C., Raczynski, J., Heath, G., Levinson, R. and Cutter, G. (1993b) Physical activity of public housing residents in Birmingham, Alabama. American Journal of Public Health 83, 1016-1020.

Lirgg, C. (1991) Gender differences in self-confidence in physical activity: A meta-analysis of recent studies. US Journal of Sport and Exercise Psychology 13, 294-310.

Lissner, L., Bengtsson, C., Bjorkelund, C. and Wedel, H. (1996) Physical activity levels and changes in relation to longevity. American Journal of Epidemiology 143, 54 62.

Liu, K., Ruth, K., Flack, J., Jones-Webb, R., Burke, G., Savage, P. and Hulley, S. (1996) Blood pressure in young blacks and whites. The CARDIA Study. Coronary artery risk development in young adults. Circulation 93, 60-66.

Lombard, D., Lombard, T. and Winett, R. (1995) Walking to meet health guidelines - the effect of prompting frequency and prompt structure. Health Psychology 14, 164-170.

Luschen, G., Cockerham, W. and Kunz, G. (1996) The sociocultural context of sport and health problems of causal relations and structural interdependence. Sociology of Sport Journal 13, 197-213.

Macera, C., Croft, J., Brown, D., Ferguson, J. and Lane, M. (1995) Predictors of adopting leisure time physical activity among a biracial cohort. American Journal of Epidemiology 142, 629-635.

Mackenbach, J., van den Bos, J., Joung, I., van de Mheen, H. and Stronks, K. (1994) The determinants of excellent health: Different from the determinants of illhealth? International Journal of Epidemiology 23, 12731281.

Marcus, B. and Simkin, L. (1994) The transtheoretical model: Applications to exercise behaviour. Medicine and Science in Sports and Exercise 26, 1400-1404.

Marino, S., Gallo, J., Ford, D. and Anthony, J. (1995) Filters on the pathway to mental health care Psychological Medicine 25, 1135-1148. 
Martin, L., Friedman, H., Schwartz, J., Tucker, J., Criqui, M., Wingard, D. and Tomlinson-Keasey, C. (1995) An archival prospective study of mental health and longevity. Health Psychology 14, 381-387.

Mcdermott, L. (1996) Toward a feminist understanding of physicality within the context of women's physically active and sporting lives. Sociology of Sport Journal 13, 12-30.

Meek, J. (1993) An analysis of comprehensive health promotion programs' consistency with the systems model of health. American Journal of Health Promotion 7, 443451

Melillo, K., Futrell, M., Williamson, E., Chamberlain, C., Bourque, A., MacDonnell, M. and Phaneuf, J. (1996) Perceptions of physical fitness and exercise activity among older adults. Journal of Advanced Nursing 23, $542-547$.

Mensink, G., Deketh, M., Mul, M., Schuit, A. and Hoffmeister, H. (1996) Physical activity and its association with cardiovascular risk factors and mortality. Epidemiology 7, 391-397.

Michielutte, R., Dignan, M., Wells, H., Young, L., Jackson, D. and Sharp, P. (1989) Development of a community cancer education program. Public Health Reports 104, 542-551.

Midanik, L., Soghikian, K., Ransom, L. and Tekawa, I. (1995) The effect of retirement on mental health and health behaviours. Journal of Gerontology 50, S59-S61.

Milio, N. (1986) Promoting health through public policy. Canadian Public Health Association, Ottawa.

Millar, W. and Stephens, T. (1993) Social status and health risks in Canadian adults. Health Reports 5, 143156.

Mills, K., Stewart, A., King, A., Roitz, K., Sepsis, P., Ritter, P. and Bortz, W. (1996) Factors associated with enrollment of older adults into a physical activity promotion program. Journal of Aging and Health 8, 96113.

Muraki, S., Maehara, T., Ishii, K., Ajimoto, M. and Kikuchi, K. (1993) Gender difference in the relationship between physical fitness and mental health. Annals of Physiological Anthropology 12, 379-384.

National Cancer Institute (1995) Theory at a glance: $A$ guide for health promotion practice. National Institutes of Health, Washington, DC.

O'Neill, J. (1993) Ecology, policy, and politic. Routledge, London.

Omodei, M. and Wearing, A. (1990) Need satisfaction and involvement in personal projects: Toward an integrative model of subjective well-being. Journal of Personality and Social Psychology 59, 762-769.

Ontario Premier's Council on Health Strategy (1991) Towards health outcomes: Objectives and targets. Toronto.

Ontario Public Health Association (1994) Determinants of Health. Toronto.

Opdycke, R., Ascione, F., Shimp, L. and Rosen, R. (1992) A systematic approach to educating elderly patients about their medications. Patient Education and Counselling 19, 43-60.

Ormel, J., Stewart, R. and Sanderman, R. (1989) Personality as modifier of the life change-distress relationship: A longitudinal modelling approach. Social Psychiatry and Psychiatric Epidemiology 24, 187-195.

Osipow, S. and Fitzgerald, L. (1993) Unemployment and mental health. Applied and Preventive Psychology 2, 5963.

Osler, M. (1993) Social class and health behaviour in Danish adults. Public Health 107, 251-260.

Palank, C. (1991) Determinants of health-promotive behaviour. Nursing Clinics of North America 26, 815-832.
Paraschak, V. (1997) Variations in race relations - sporting events for Native peoples in Canada. Sociology of Sport Journal 14, 1-21.

Pate, R., Pratt, M., Blair, S., Haskell, W., Macera, C. Bouchard, C., Buchner, D., Ettinger, W., Heath, G. and King, A. (1995) Physical activity and public health. JAMA 273, 402-407.

Pate, R., Heath, G., Dowda, M. and Trost, S. (1996) Associations between physical activity and other health behaviours. American Journal of Public Health 6, 1577 1581

Philipp, S. (1994) Racial differences in perceived leisure constraints. Perceptual and Motor Skills 79, 1339-1343.

Philipp, S. (1995) Race and leisure constraints. Leisure Sciences 17, 109-120.

Pitter, R. and Andrews, D. (1997) Serving Americas underserved youth-reflections on sport and recreation in an emerging social problems industry. Quest 49, 85-99.

Polcyn, M., Price, J., Jurs, S. and Roberts, S. (1991) Utility of the PRECEDE model in differentiating users and nonusers of smokeless tobacco. Journal of School Health 61, 166-171.

Pollard, J. and Storper, M. (1996) A tale of twelve cities metropolitan employment change in dynamic industries in the 1980s. Economic Geography 72, 1-22.

Puddey, I. and Beilin, L. (1995) Exercise in the prevention and treatment of hypertension. Current Opinion in Nephrology and Hypertension 4, 245-250.

Quinney, A., Gauvin, H. and Wall, T. (1994) Community Determinants of Active Living, Proceedings of the International Conference on Physical Activity, Health and Fitness. Human Kinetics, Toronto.

Rabinowitz, S., Melamed, S., Kasan, R. and Ribak, J. (1993) Personal determinants of health promoting behaviour. Public Health Reviews 20, 5-14.

Reeves, J. and Szafran, R. (1996) For what and for whom do you need more time. Time and Society 5, 237-251.

Richard, L., Potvin, L., Kischuk, N., Prlic, H., Green, L. (1996) Assessment of the integration of the ecological approach in health promotion programs. American Journal of Health Promotion 10.

Richardson, V. and Kilty, K. (1995) Gender differences in mental health before and after retirement. Journal of Women and Aging 7, 19-35.

Richardson, M., Leon, A., Jacobs, D., Ainsworth, B. and Serfass, R. (1994) Comprehensive evaluation of the Minnesota Leisure Time Physical Activity Questionnaire. Journal of Clinical Epidemiology 47, 271281.

Richardson, M., Ainsworth, B., Wu, H., Jacobs, D. and Leon, A. (1995) Ability of the atherosclerosis risk in communities/Baecke questionnaire to assess leisure-time physical activity. International Journal of Epidemiology 24, 685-693.

Ross, C. and Wu, C. (1995) The links between education and health. American Sociological Review 60, 719-745.

Rudman, W. (1989) Age and involvement in sport and physical activity. Sociology of Sport Journal 6, 247-256.

Ruffing-Rahal, M. (1993) An ecological model of group well-being: Implications for health promotion with older women. Health Care for Women International 14, 447456.

Sage, G. (1986) Social Development. In Physical Activity and Well-being, ed. V. Seefeldt, pp. 343-371. American Alliance for Health, Physical Education, Recreation and Dance, Reston, VA.

Sallis, J., Hovell, M., Hofstetter, C., Faucher, P., Elder, J., Blanchard, J., Caspersen, C., Powell, K. and Christenson, G. (1989) A multivariate study of determinants of vigorous exercise in a community sample. Preventive Medicine 18, 20-34.

Sallis, J., Zakarian, J., Hovell, M. and Hofstetter, C. (1996) Ethnic, socioeconomic, and sex differences in 
physical activity among adolescents. Journal of Clinical Epidemiology 49, 125-134.

Shephard, R. and Bouchard, C. (1994) Population evaluations of health related fitness from perceptions of physical activity and fitness. Canadian Journal of Applied Physiology 19, 151-173.

Shephard, R. and Bouchard, C. (1996) Associations between health behaviours and health related fitness. British Journal of Sports Medicine 30, 94-101.

Shinew, K., Floyd, M., Mcguire, F. and Noe, F. (1995) Gender, race, and subjective social class and their association with leisure preferences. Leisure Sciences 17, $75-89$

Siegel, P., Brackbill, R. and Heath, G. (1995) The epidemiology of walking for exercise-implications for promoting activity among sedentary groups. American Journal of Public Health 85, 706-710.

Sobal, J., Revicki, D. and DeForge, B. (1992) Patterns of interrelations among health-promotion behaviours. American Journal of Preventive Medicine 8, 351-359.

Sonstroem, R., Harlow, L., Gemma, L. and Osborne, S. (1991) Test of structural relationships within a proposed exercise and self-esteem model. Journal of Personality Assessment 56, 348-364.

Statistics Canada (1994) Health status of Canadians: Report of the 1991 General Social Survey. Ottawa, Ont.

Statistics Canada (1995) Nationalpopulation health survey overview. Ottawa, Ont.

Stephens, T. and Craig, C. (1990) The well-being of Canadians: Highlights of the 1988 Campbell's Survey. Ottawa. Canadian Fitness and Lifestyle Institute.

Stewart, G. (1995) Active living - the miracle medicine for a long and happy life. Human Kinetics, Champaign, IL.

Strawbridge, W., Cohen, R., Shema, S. and Kaplan, G. (1996) Successful aging: Predictors and associated activities. American Journal of Epidemiology 144, 135-141.

Sundquist, J. (1995) Living conditions and health. Scandinavian Journal of Primary Health Care 13(Suppl.),

Thibault, J. (1980) Aging and Leisure: A Social Psychological Perspective. In Social psychological perspectives on leisure and recreation. eds. Iso-Ahola, Seppo. Charles C. Thomas, Springfield, IL.

Thomas, S. and Graham, D. (1993) Canada's health promotion survey 1990. Health and Welfare Canada.

Tinsley, H. and Eldredge, B. (1995) Psychological benefits of leisure participation. Journal of Counselling Psychology 42, 123-132.

Toth, J. and Brown, R. (1997) Racial and gender meanings of why people participate in recreational fishing. Leisure Sciences 19, 129-146.

Trost, S., Pate, R., Dowda, M., Saunders, R., Ward, D. and Felton, G. (1996) Gender differences in physical activity and determinants of physical activity in rural fifth grade children. Journal of School Health 66, 145-150.

Trost, S., Pate, R., Saunders, R., Ward, D., Dowda, M. and Felton, G. (1997) A prospective study of the determinants of physical activity in rural fifth-grade children. Preventive Medicine 26, 257-263.

Uitenbroek, D. (1993a) Relationships between leisure time physical activity for exercise and other health-related behaviours. Sozial und Praventivmedizin 38, 356-361.

Uitenbroek, D. (1993b) Seasonal variation in leisure time physical activity. Medicine and Science in Sports and Exercise 25, 755-760.

Underwood, E., van Berkel, C., Scott, F., Siracusa, L. and Gibson, B. (1993) The environmental connection. Canadian Nurse 89, 33-35.
Unger, J. and Johnson, C. (1995) Social relationships and physical activity in health club members. American Journal of Health Promotion 9, 340-343.

Valois, P., Desharnais, R. and Godin, G. (1988) A comparison of the Fishbein and Ajzen and the Triandis attitudinal models for the prediction of exercise intention and behaviour. Journal of Behavioral Medicine 11, 459472.

Verbrugge, L., Gruber-Baldini, A. and Fozard, J. (1996) Age differences and age changes in activities: Baltimore Longitudinal Study of Aging. Journal of Gerontology 51, S30-S41.

Walker, S., Sechrist, K. and Pender, N. (1987) The healthpromoting lifestyle profile: Development and psychometric characteristics. Nursing Research 36, 76-81.

Wankel, L. (1993) The importance of enjoyment to adherence and psychological benefits from physical activity. International Journal of Sport Psychology 24, 151-169.

Wenger, N. (1996) Physical inactivity and coronary heart disease in elderly patients. Clinics in Geriatric Medicine 12, 79-88.

Weyerer, S. and Kupfer, B. (1994) Physical exercise and psychological health. Sports Medicine 17, 108-116.

Whaley, M. and Blair, S. (1995) Epidemiology of physical activity, physical fitness and coronary heart disease. Journal of Cardiovascular Risk 2, 289-295.

Whittemore, K. (1994) Studies in mental health policy-suggestions for future research. Policy Studies Journal 22, 691-693.

Wigle, D., Evans, R., Barer, M. and Marmor, T. (1995) Why are some people healthy and other not - the determinants of health of populations. Canadian Journal of Public Health 86, 213.

Williams, S. (1994) Environment and mental health, J. Wiley, Chichester, New York.

Wolf, A., Gortmaker, S., Cheung, L., Gray, H., Herzog, D. and Colditz, G. (1993) Activity, inactivity, and obesity: Racial, ethnic, and age differences among schoolgirls. American Journal of Public Health 83, 1625-1627.

Woodward, D., Green, E. and Hebron, S. (1989) The sociology of women's leisure and physical recreation: Constraints and opportunities. International Review for the Sociology of Sport 24(2), 121-134.

World Health Organization (1986) "The Ottawa Charter for health promotion." Health Promotion, 3-5.

Wright, J. (1996) Mapping the discourses of physical education-articulating a female tradition. Curriculum Studies 28, 331-351.

Yeager, K. and Macera, C. (1994) Physical activity and health profiles of United States women. Clinics in Sports Medicine 13, 329-338.

Yeager, K., Macera, C. and Merritt, R. (1993) Socioeconomic influences on leisure-time sedentary behaviour among women. Health Values: Achieving High Level Wellness 17, 50-54.

Yoshida, K., Allison, K. and Osborn, R. (1988) Social factors influencing perceived barriers to physical exercise among women. Canadian Journal of Public Health 79, 104-108.

Yoshioka, C. (1988) Social groups and determinants of leisure behaviour. International Review of Modern Sociology 18, 61-69.

Yusuf, H., Croft, J., Giles, W., Anda, R., Casper, M., Caspersen, C. and Jones, D. (1996) Leisuretime physical activity among older adults. United States, 1990 Archives of Internal Medicine 156, 1321-1326.

Zanger, B. and Groves, D. (1994) A framework for the analysis of theories of sport and leisure management. Social Behaviour and Personality 22, 57-67. 